\title{
Special issue - coastal dune slack hydro-ecology
}

\author{
Charlie Stratford $^{1} \cdot$ Paul Rooney ${ }^{2}$
}

Published online: 10 October 2017

(C) Springer Science+Business Media B.V. 2017

\section{Introduction}

Coastal dune slack wetlands exist at the interface between land and sea. They typically occur in the low-lying areas between dune ridges where the water table remains at or near the ground surface for some or all of the year. Like many wetland habitats, the hydro-ecological conditions provide a niche in which specially adapted species can exist. Notable dune slack species with European protection include the natterjack toad (Bufo calamita) and the fen orchid (Liparis loeselii).

Dune systems are amongst the most dynamic of all habitats and dune wetlands can appear or disappear in timescales comparable to human lifespans as coastal processes deposit or erode the substrates upon which they form. It is these dynamic processes that create areas of bare sand suitable for development of early successional stages of dune vegetation whilst elsewhere in the dune system natural succession drives a progression towards more mature vegetation.

Over time, anthropogenic pressures including afforestation, abstraction and addition of nutrients have resulted in a decline in the quality and extent of dune habitat such that the majority of humid dune slacks across Europe are now in unfavourable condition. Management to address these pressures and improve dune habitats is underway in many countries however

Charlie Stratford

cstr@ceh.ac.uk

1 Centre for Ecology and Hydrology, Wallingford, Oxfordshire OX10 8BB, UK

2 Geography Department, Faculty of Science and Social Science, Liverpool Hope University, Hope Park, Liverpool L16 9JD, UK the complex mix of natural and anthropogenic processes that influence dune wetlands is at times difficult to disentangle making it hard to identify the most suitable management practices at particular sites.

Up to now effective management of these habitats has not been supported by a coordinated presentation of the relevant research. The establishment of multidisciplinary groups such as the UK Sand Dune and Shingle Network has proved effective in bringing together the range of expertise necessary to affect change. This special issue is the result of the second meeting of the network's Sand Dune Hydrology Group which was held in Swansea in September 2013 with the intention of supporting effective habitat management through sound science.

\section{The situation in the UK}

Coastal dune slacks have been the focus of scientific research for many decades and it was arguably the work of Ranwell (1959) at Newborough Warren that first started to quantify the relationship between hydrological regime and presence of a particular wetland plant community. An extensive vegetation survey of Great Britain's coastal dune wetlands was undertaken in the late 1980s and early 1990s (Doody 2005). The survey had two aims:

1. To produce a vegetation map (in accordance with National Vegetation Classification (NVC) methodologies) and description for each sand dune system which will be useful to those directly involved in conservation;

2. To produce a national inventory of the range and extent of sand dune habitats in Great Britain. Such an inventory will then allow the interest of any particular site or group of sites to be placed in its national context. 
In 2012, Centre for Ecology and Hydrology carried out a repeat NVC botanical survey of dune slacks at eight of the larger English coastal sites with dune slack habitat. In addition to vegetation, this survey sampled and analysed soils from each site and provided a conceptual hydrological understanding. The idea behind this was to provide more of the circumstantial information required to explain changes to the dune slack plant communities over time and to identify potential restoration methods where required. This study concluded that with comparison to 1990 , there had been a net loss in dune slack habitat across the majority of sites (Stratford et al. 2014). The need to develop our understanding of the drivers of habitat change, which forms the basis of this special issue, is due in part to the findings of this study.

In a European context, this message has recently been reiterated following the workshop on dunes and estuaries held at the 2nd Atlantic Biogeographic Seminar, in October 2016 (Natura 2000 2016). An outline roadmap for knowledge exchange and networking to support the conservation of dune habitats identifies amongst other things, the following priorities for collaboration:

- developing and promoting a joint research programme on issues with an explicit international dimension e.g. impacts of $\mathrm{N}$-deposition and climate change,

- guidelines on how to incorporate dynamics into the interpretation of Favourable Conservation Status,

- further interpretation of habitat types, especially fixed dune and slack sub-types and

- expected changes to habitats as dune systems respond to climate change pressures.

Our experience both through detailed sharing of hydro-ecological research across UK dune sites and through networking with colleagues throughout Europe is that knowledge exchange is very effective in supporting better restoration outcomes in a more efficient manner. To facilitate this, the Sand Dune and Shingle Network established a Hydrology Thematic Group, led by Centre for Ecology and Hydrology. The group has convened two meetings (in 2010 and 2013) with the aim of supporting the ongoing exchange of knowledge between researchers and practitioners. We welcome you to become part of this process. A map of dune sites in Great Britain where hydrological and/or ecological research is taking or has taken place has been assembled through input from members of the thematic group (Fig. 1). If you are aware of research that we have missed then please get in touch with the Hydrology Thematic Group via email: dunes@hope.ac.uk.
Dune hydrology thematic group meeting on 'dealing with dynamics and extremes', 9th to 11th September 2013, Swansea, South Wales, UK

A 3 day meeting consisting of presentations and field visits was held in Swansea, South Wales in September 2013 in order to bring together researchers, managers and policy makers and share current knowledge and experience. The papers in this special issue are derived from the presentations given at that meeting. The breadth of papers, covering aspects from hydrological and hydro-chemical processes to new techniques for monitoring vegetation dynamics, reflect the range of disciplines that took an active part in the meeting. Effective management of coastal dune slack wetlands requires a multidisciplinary approach and the papers in this special issue describe relevant aspects of hydrology, vegetation and anthropogenic pressures.

The first set of papers considers hydrological aspects of dune slacks. Pieter Stuyfzand presents an overview of hydrological observations made in the Netherlands, including the famous Castricum mega-lysimeter experiments that quantified groundwater recharge rates under various types of vegetation. This and other work has supported the development of a modelling tool box that includes tools to estimate groundwater recharge as function of rainfall and vegetation, and the potential effects of various interventions.

The challenges of using numerical models to represent small groundwater systems, typical of those found in coastal dunes, are explored by Corinna Abesser and Derek Clarke with reference to two UK sites: Braunton Burrows and Ainsdale Sands. The application of conventional groundwater modelling approaches to these small systems presents a number of challenges due to the local scale of the system and the fact that the system boundaries (sea, drains, ponds etc.) are close to the main body of the aquifer. The paper demonstrates that, although conventional hydraulic models can describe the general system behaviour, a fuller understanding of the recharge mechanisms and system boundaries is needed to represent adequately system dynamics of small groundwater systems.

Initial site investigations often aim to help formation of a conceptual understanding of the hydrological system - that is a qualitative description of the main hydrological drivers and pathways. Once this is in place, more detailed investigations can be carried out to quantify those aspects and refine the conceptual understanding. Nick Robins and Paul Wilson present a conceptual snapshot of the Magilligan dune system in Northern Ireland which is unusual because unlike many other sites with humid dune slacks in the British Isles the sand is not wholly underlain by silt and clay, but underlain in part by raised beach sand and gravel deposits. The result is that rather than discharging towards the sea, much of the discharge from the sand aquifer occurs via the underlying permeable deposits. 


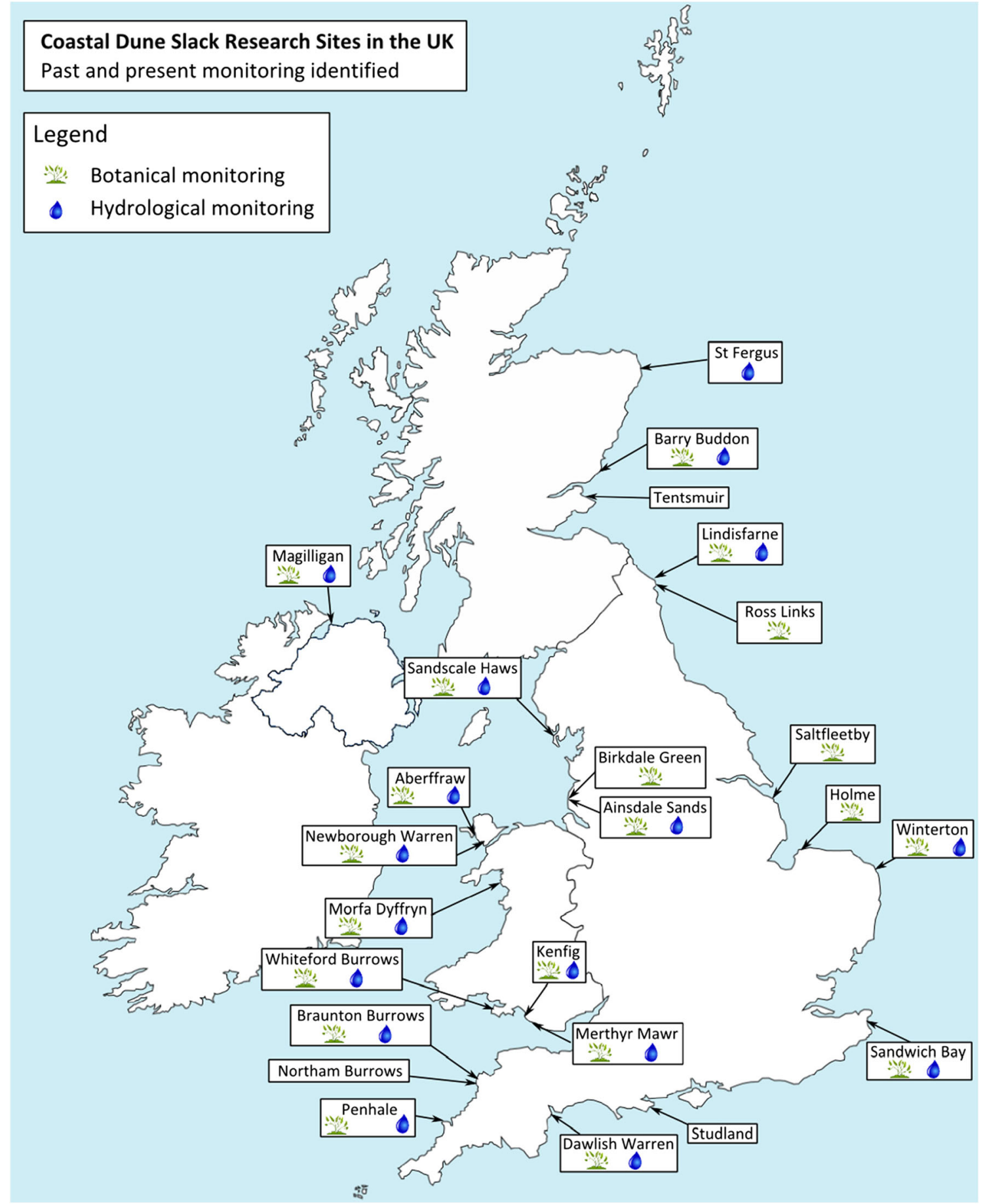

Fig. 1 Coastal dune slack research sites in the UK. As identified by the Sand Dune and Shingle Network Hydrology Thematic Group

The second set of papers looks at dune slack vegetation. The paper by Peter Jones et al. discusses the influence of seasonal changes in water levels on the floristic composition of plant communities within the dunes at Kenfig Burrows NNR. Kenfig is one of the largest dune sites in South Wales and southern Britain and one of the very few UK dune sites to still support a population of the fen orchid Liparis loeselii. Key factors governing the annual hydrological budget of the dune system aquifer are discussed in relation to their impact on vegetation communities.

The population dynamics of Liparis loeselii are further investigated in the paper by Ab Grootjans et al., through detailed assessment of populations on six Wadden Sea islands. The occurrence of the orchid was related to soil factors and hydrological conditions and the window of opportunity for colonisation of a new slack was found to be relatively narrow. 
Soil $\mathrm{pH}$ and organic matter content were found to correlate with the occurrence of $L$. loeselii populations and large populations were associated with young slacks in which anoxic calcareous groundwater influenced the top soils.

Monitoring of dune vegetation using traditional field survey techniques is time-consuming and costly, and although necessary to provide the high-quality periodic datasets required for some reporting objectives, is not practical for regular repeat surveys. An alternative approach using remote sensing data (a combination of LIDAR and CASI) and Object Orientated Image Analysis is presented in the paper by Jonathan Brownett and Rachael Mills. Accuracy assessments have shown this approach to be successful and eleven UK sites have been mapped to date. These techniques are providing a new approach to monitoring change in coastal vegetation communities and informing management of protected sites.

The final set of papers investigate a range of pressures impacting on coastal dunes and how those are dealt with through appropriate management. Luc Geelen et al., discuss the evolution of the Dutch coastal dunes which, since 1853, have been used for abstraction of groundwater to produce drinking water. The dune slacks largely disappeared as a result and wetland biodiversity declined. From the late 1980s, a series of measures have been implemented to address this decline, such as the filling-up of recovery canals, mowing, grazing and sod-cutting. The paper presents the results of these measures in terms of the restoration of natural hydrological conditions and recovery of wet slack vegetation.

Nitrogen enrichment is a potential cause of poor condition for wetland vegetation. Mark Whiteman et al. discuss the application of nitrate threshold values with reference to the case study site, Merthyr Mawr, South Wales. Groundwater discharging from the underlying Carboniferous Limestone creates a large dune slack however water quality problems associated with management of the surrounding land are shown to be impacting on the vegetation in the slack, which is in unfavourable condition. The groundwater catchment is complex and land management changes to reduce nutrient pressure are an ongoing challenge.

The final paper describes the evolution of Kenfig Burrows from its initial formation as a sand barrier system and subse- quent migration in land. Ken Pye and Simon Blott investigate the combined impact of declining marine sand supply and changes in meteorological conditions accompanied by reduced grazing and physical disturbance, on the dune habitat. The result is a dune system with declining sand mobility and consequent impact on the early successional plant communities that favour bare sand in which to establish. The paper describes some recent trials looking at increasing sand mobility using techniques such as turf stripping and creation of 'notches' in the frontal dunes.

It is hoped that this special issue will help to highlight some of the excellent research carried out on dune slack wetlands in recent years and in doing so will both support ongoing restoration and promote further collaboration between the academic and practitioner communities.

Acknowledgements The guest editors would like to thank all authors who have contributed to this special issue. We would also like to thank the organisations that funded the workshop upon which this special issue is based: Centre for Ecology and Hydrology, British Geological Survey, Natural England, Natural Resources Wales and Liverpool Hope University.

\section{References}

Doody JP (2005) Sand dune inventory of Europe. In: Herrier J-L, Mees J, Salman A, Seys J, Van Nieuwenhuyse H, Dobbelaere I (eds) Proceedings 'dunes and estuaries 2005' - International conference on nature restoration practices in European coastal habitats. Koksijde, Belgium, p 47

Natura 2000 (2016) Outline of a roadmap for knowledge exchange and networking for the period 2016-2020, Conservation of dune habitats in the Atlantic Biogeographic Region. Available at http://ec.europa. eu/environment/nature/natura2000/platform/documents/263/ Roadmap_for_dunes_of_the_Atlantic_Region_v_Jan2017_en.pdf. Accessed 8 Oct 2017

Ranwell D (1959) Newborough Warren, Anglesey: I. The dune system and dune slack habitat. J Ecol 47:571-601

Stratford C, Jones L, Robins N, Mountford O, Amy S, Peyton J, Hulmes LSH, Jones F, Redhead J, Dean H, Palisse M (2014) Survey and analysis of vegetation and hydrological change in English dune slack habitats, Natural England Commissioned Report NECR153. Natural England, Peterborough, pp 1-98 